\title{
Computed Spanish/Hispanic Ethnicity Code
}

National Cancer Institute

\section{Source}

National Cancer Institute. Computed Spanish/Hispanic Ethnicity Code. NCI Thesaurus.

Code C160895.

Code identifying individuals for which ethnicity was determined by matching Last Name and Maiden Name to a computer list of Spanish/Hispanic names or by a software algorithm. 